\title{
O DEBATE ENTRE MART SUSI (IBF) E ROBERT ALEXY (WF), ORGANIZADO NA OBRA PROPORCIONALIDADE E INTERNET
}

Lucas Reckziegel Weschenfelder ${ }^{1}$

Luiz Gonzaga Silva Adolfo²

Recebido em 14 de outubro de 2020

Aceito em 14 de outubro de 2020

\section{Noções introdutórias ao debate}

O livro Proporcionalidade e Internet é oriundo de uma discussão teórica entre Mart Susi e Robert Alexy, no que diz respeito à ponderação na esfera "online". Realiza-se, primeiro, uma explanação dos pressupostos teóricos da ponderação "online" (IBF). Posteriormente, mostram-se os argumentos de Alexy sobre a fórmula WF e sua relação com a IBF. Ao fim, destaca-se a fórmula IBF "revisitada", mediante uma análise conjunta, conduzida por Susi.

As articulações de Susi, apesar de baseadas na ponderação alexyana, são condicionadas por observações que demonstram as discrepâncias entre ambas as posturas. $O$ ponto da IBF é: considerando-se o novo paradigma do "online", em que conflitos entre direitos ocorrem ou podem ocorrer, é imperativo uma nova proporcionalidade, a ser aplicada nessa esfera. Releva-se que a "ponderação "off-line" é baseada no entendimento de que os direitos em possível conflito possuem a mesma importância antes do "processo de ponderação". Por exemplo, a liberdade de expressão e a privacidade detêm um igual forte normativo antes de haver uma situação que demonstre, aparentemente, um conflito de normatividade entre esses direitos, no qual, posteriormente, com o exercício da ponderação, um deles poderá prevalecer. Essa concepção de "igual importância dos direitos em conflito" é colocada, igualmente, na esfera digital, com fundamento no que se denomina de monotonia dos direitos "off-line" e "online", notadamente, pela noção, consensualmente, prédisposta de "independência prática dos direitos fundamentais ou na universalidade desses direitos". Um dos problemas em relação a essa doutrina surge em fundamentações ou discursos que imprimem uma noção contrária, que passam a compreender que os direitos em possível conflito não comportam um a priori igualitário de carga normativa. Ambas as perspectivas, diz Susi, são relevantes. Entretanto, tanto a primeira como a segunda vêm sendo aplicadas nos Tribunais Europeus (Direitos Humanos, de Justiça e cortes nacionais).

\footnotetext{
1 Mestre em Direito pela Universidade de Santa Cruz do Sul; pós-graduando em Direito do Trabalho pela Universidade Federal do Rio Grande do Sul; Advogado; https://orcid.org/0000-0001-9297-7465; lucasweschen@yahoo.com.br

2 Pós-doutor em Direito pela Pontifícia Universidade Católica do Rio Grande do Sul; Doutor em Direito pela Universidade do Vale dos Sinos; Professor no Programa de Pós-Graduação em direito da Universidade de Santa Cruz do Sul; https://orcid. org/0000-0003-3786-3590; adolfo@unisc.br
} 
No caso das empresas intermediárias, contudo, essa preocupação não aparece, embora elas (as empresas) estejam criando seus próprios critérios decisórios, uma vez que, querendo-se ou não, essas empresas estão decidindo casos de conflitos entre direitos. Esse horizonte é, justamente, o lócus de onde Susi retira a sua afirmação e crítica de que o paradigma da ponderação passou, na esfera "online", por uma mudança, vista no ignorar da ideia de pesos iguais a direitos, "substituída" por uma prática advinda dos critérios concretizados pelos próprios atores privados - o peso aos direitos é atribuído por eles e é, nesse setor, com seus contextos particulares, que a fórmula IBF pretende se inserir, enquanto um "método" público de resolução racional de conflitos de direitos na internet.

\section{0 papel, a capacidade das empresas intermediárias e a horizontalidade ou verticalidade dos direitos}

Algumas bases, rotineiramente colocadas como problemáticas, no que diz respeito à "ponderação online", precisam ser observadas criticamente. i) De que qualquer avaliação de conteúdo se interconecta com o conceito de censura; ii) a qual o Estado estaria delegando o exercício da censura para as empresas privadas; iii) a noção de que a ponderação online, realizada por um "agente público" e um empregado privado, nesse contexto particular, seriam amplamente distintas, quando da análise de um conteúdo consensualmente construído como ilícito; e iv) a divergência entre a horizontalização dos direitos humanos ou verticalização, e as consequências jurídico-constitucionais de cada espectro sobre o tema. Em outra perspectiva, vale ressaltar a preocupação com a capacidade das empresas privadas em apreciar o conteúdo "online", que suas plataformas fornecem aos usuários. Percebe-se que as Cortes e órgãos legislativos internacionais não se preocupam, quando dos pareceres ou decisões, com o fato de as empresas privadas reivindicarem alguma "autoridade moral" na garantia de direitos. Pode-se afirmar que a capacidade de ponderação das empresas "online" tem a ver com um questionamento sobre a habilidade de empresas realizarem ponderações, via atribuição de pesos a direitos em conflito e justificarem essa atribuição de pesos, sem se caracterizarem por uma condução de soluções meramente arbitrárias, porque, afinal, essas empresas realizam a apreciação dos conteúdos no "online".

Nota-se que a incapacidade "logística" de avaliação sobre os conteúdos "online" nunca foi manifestada por empresas grandes do ramo e supõe-se que essa dificuldade poderá ser encontrada nas empresas de menor porte. Nesse cenário, ao mesmo tempo, nunca houve um pronunciamento minucioso sobre os critérios que essas empresas intermediárias empregam na apreciação de conteúdo, e essa incapacidade epistêmica, diz Susi, não pode levar à compreensão de que os processos de apreciação não sejam sustentados pela boa-fé e lealdade.

Disso resulta a conclusão de definir que o que importa, pois, é como a ponderação é compreendida, independentemente da "transparência" quanto ao processo mesmo, no tocante a uma possível análise retrospectiva sobre como os pesos dos direitos foram estabelecidos nas 
avaliações, sendo relevante observar, preponderantemente, o próprio resultado do exercício de ponderação, visto como uma "ordenação" dessa prática de resolução de conflitos de direitos, de como os critérios disponíveis publicamente são aplicados nessas avaliações. Há, ainda, no observar de Susi, um nível contestatório sobre esse tema, precisamente devido ao quesito "transparência". As empresas intermediárias alegam que a "transparência" é uma qualidade impossível de se atingir, devido a questões contextuais da resolução de conflitos no "online": milhares de conflitos e pouco tempo para solucioná-los. Entretanto e complementando esse cenário ainda contraditório, se se entender como bastante a perspectiva dos "resultados" da ponderação online, a partir de critérios normativos públicos, a "transparência", com efeito, deixará de ser uma reivindicação imprescindível para a ponderação "online".

\section{Complementações teóricas entre Robert Alexy e Mart Susi}

A fórmula IBF: o aspecto "ôntico", "epistêmico" e seus elementos formadores - A fórmula IBF pretende trazer racionalidade para o exercício da ponderação "online". Essa racionalidade é dependente da possibilidade de se observar a ponderação em caracteres de justificação "ôntica" e "epistêmica". O lado "ôntico" quer demonstrar a relação entre os direitos em conflito a serem ponderados, enquanto o aspecto "epistêmico" cuida da praticabilidade de se exercer a ponderação no "online", satisfatoriamente. No que diz respeito ao aspecto ôntico, trata-se da indagação de se a teoria da monotonia deve ser aplicada no "online". E se o consenso no mundo "off-line", segundo o qual os direitos detêm os mesmos pesos a priori, antes de um conflito, se aplica na esfera "online". A fórmula IBF expressa que a vulnerabilidade na internet proporciona uma "condição ôntica", que altera os antecipados "pesos" entre direitos em conflito em uma prática ponderativa. Assim, é razoável esperar de um contexto "no online", em que o direito à privacidade é preponderante, a produção de um "equilíbrio" se o "peso relativo de outros fatores" postos em contraposição produzir um "equilíbrio" ideal entre as dimensões dos direitos em embate. Na esfera epistêmica, tem-se a preocupação com as condições reais de decisão pelas empresas intermediárias, considerando a impossibilidade "fática" de "fundamentar" milhares de decisões em tempo "hábil". A IBF pretende resolver esses impasses. A preocupação com a arbitrariedade é resolvida pelo dever de aplicação da mesma fórmula para todos os casos de conflito de direitos, a ausência de transparência pelo conhecimento dos usuários de que a fórmula IBF foi empregada para a resolução do conflito, e que os critérios para a apreciação são produzidos por uma fórmula, cujo resultado origina-se de uma fundamentação "matemática". Essa dinâmica representa a viabilidade de uma pretensão de correção.

Bases teóricas da ponderação "online" - Considerando a incapacidade de as transformações e novidades na esfera "online" serem previstas, a IBF torna-se "um instrumento vivo para a proteção de direitos fundamentais", devendo-se manter sempre aberto às transformações "ônticas" e "epistêmicas", sendo isso, a propósito, uma observação que levou à sua própria elaboração. 
Além dessa base, tem-se que a fórmula IBF é caracterizada pelos seguintes pressupostos: i) não será possível o método IBF embaraçar informações de interesse público; ii) o método é inspirado na teoria alexyana, de introdução da matemática como orientação de decisões judiciais sobre direitos humanos; iii) os elementos de entrada da fórmula IBF se baseiam nos mesmos encontrados nos tribunais europeus, em especial no Tribunal Europeu de Direitos Humanos, e por elementos próprios, oriundos das novas condições ônticas e epistêmicas do "online"; iv) A fórmula IBF não se aplica quando o conteúdo possui relação com o que se compreende por verdade histórica em uma dada sociedade considerada historicamente. $O$ pensamento é o mesmo do qual se retira a inaplicabilidade de ponderação para os casos de discurso de ódio. Enfim, é inaplicável ao consensualmente estabelecido sobre determinado conteúdo orientado por ser uma "verdade histórica" ou relacionado a um "discurso de ódio"; v) a fórmula deve ser universal e aplicada por todos, desnecessitando treinamento legal ou estudo técnico sobre a proteção de direitos humanos, devendo-se conduzir por uma experiência empírica. A fórmula IBF constitui-se em um valor numérico, relacionado como um i) resultado de elementos de entrada para o direito à esfera privada ii), dividido pelo valor numérico associado à liberdade de expressão iii) como um resultado de elementos de entrada.

Os elementos do direito à esfera privada - Os elementos na IBF, que representam o direito à esfera privada, são os seguintes: $\mathrm{V}(1)+\mathrm{PR}(\mathrm{x})+\mathrm{T}(\mathrm{y})$. V equivale à vulnerabilidade existente na internet no que toca ao direito à esfera privada, representada pelo valor numérico constante 1. PR representa o elemento de interferência na esfera privada, cujo valor numérico poderá ser de 1 a 3 (leve 1, moderada 2, intensa 3), e o x coloca-se como o nível dessa intensidade. É importante ressalvar que esse valor não dependerá de qualquer subjetividade, mas advirá da "percepção de um espectador neutro". T retrata o fator Tempo, cuja ideia é a de que determinada interferência, com o tempo, diminui de peso, pois "a informação", paulatinamente, deixa de possuir importância, logo, de "interferir" na esfera privada. O nível dessa intensidade é enquadrado na letra y. O nível y obterá o seu valor numérico de acordo com essa escala: 0, se houver passado menos de 3 anos; 0.25, com a passagem de mais de 3 anos e menos de 7 anos; 0.5, com a passagem de mais de 7 anos e menos de 10 anos; 0.75, passagem de mais de 10 anos e menos de 13 anos; 1 passagem de mais de 13 anos.

Os elementos do direito à liberdade de expressão - $O$ direito à liberdade de expressão se apresenta, na IBF, com os seguintes elementos: P1 (x) + PF (x) - O1 (y). P1 (x) equivale ao i) nível de interesse público do conteúdo publicado, que, ii) da forma como veiculado, iii) propaga a atenção de sujeito(s) sobre uma interferência à esfera privada. O valor numérico retratará o grau do interesse público, enquanto critério objetivo. Esse grau estará interligado ao nível de impacto que determinada publicação pode ter sobre o destinatário. Os elementos de interesse público serão representados dentro de uma escala de $0,1,2,3$, simbolizados em P1, e esse nível equivalerá a x, que abarcará outros elementos relevantes. A saber, interesse público menor (1) configura o interesse público para comunidades pequenas ou com conteúdo "sensível ao tempo", cingido a um evento específico. [...] "o objeto é limitado por espaço e/ou tempo". O interesse público médio (2) enreda um interesse público 
em comunidades grandes, que "pode não ter" um impacto direto ou imediato para a "maioria". Já o interesse público significativo (3) é associado com um interesse de importância nacional ou que pode afetar, diretamente, a vida das pessoas. O nível de interesse público será 0 , quando determinada informação servir tão somente à "satisfação de curiosidade". PF, por sua vez, equivale ao elemento que indica, na liberdade de expressão, se a apreciação de um conteúdo é relacionada a uma pessoa pública. Tem-se que esse elemento é, consensualmente, relevante e é exposto na ponderação "online", consoante o conflito do direito à privacidade em face do direito de liberdade de expressão. $\bigcirc$ grau de "pública" de determinada personalidade é representado com a letra "x" e se mede pela escala 1, 2 e 3. Se uma pessoa detém um "poder público significativo", dá-se o valor numérico "3"; se uma pessoa ingressou, "voluntariamente", no "domínio público, "2"; se uma pessoa, involuntariamente, incorporou-se ao domínio público, "1". O1 destaca o elemento "modo que a informação foi obtida", fazendo-se uma importante distinção entre a liberdade de expressão e a origem e modo do conteúdo auferido. A letra y equivalerá à intensidade do grau de "reprovabilidade", pois esse elemento possui uma consequência negativa. - $\mathrm{O} 1$ (y). $\mathrm{O}$ nível será de 0 a -0.75 . -0.75 , quando a informação for ilegalmente auferida; -0.5, quando a informação for moralmente inaceitável, embora seja legalmente aceitável; -0.25, quando a informação for moralmente questionável. Susi destaca que a distinção e níveis entre moralmente errado e moralmente questionável pode se transformar com o tempo. Essa distinção é, presumivelmente, compreendida por uma "maioria de indivíduos em um grupo", correspondendo a uma "escolha racional como uma manifestação de valores sociais". O critério da legalidade detém uma natureza objetiva.

O elemento empatia - O elemento E será usado para recuperar o humano nas decisões automatizadas e será resultado de uma avaliação moral sobre os direitos colidentes (pressupondo, igualmente, que, até o momento, as inteligências artificiais não conseguem realizar juízos morais). O elemento empatia é representado pela letra " $\mathrm{E}$ ", com valores numéricos entre 0.25, 0.50, 0.75 e 1, em que a letra "z" significará esse valor. A soma de E (z) não poderá ultrapassar o valor numérico 1, considerando o peso de $\mathrm{E}$ ( $\mathrm{z}$ ) em ambos os lados da equação matemática (liberdade de expressão e esfera privada). Frisa-se que o aspecto empatia não é obrigatório em duas situações: i) quando o quociente da soma dos elementos para o direito à esfera privada, dividido pela soma dos elementos unidos à liberdade de expressão for 1; e ii) quando a própria situação de conflito de direito reivindica uma distinção de outra(s) situação(ões) comparável(eis), necessitando-se de observações de fundamentos morais, preocupadas com outros contextos "de fundo" sobre a questão, principalmente quanto à igualdade, e que podem não estar cingidos, diretamente, ao conflito de direitos em questão.

A fórmula IBF - a ponderação "online" - Assim, tem-se, com os elementos de entrada sistematizados supra, a seguinte fórmula:

$$
\mathrm{IBF}=\frac{\mathrm{V}(1)+\mathrm{PR}(\mathrm{x})+\mathrm{T}(\mathrm{y})+\mathrm{E}(\mathrm{z})}{\mathrm{P} 1(\mathrm{x})+\mathrm{PF}(\mathrm{x})-\mathrm{O} 1(\mathrm{y})+\mathrm{E}(\mathrm{z})}
$$


Desse método, retira-se o parâmetro para a decisão de direitos em conflito: se o quociente for maior que 1, o direito à esfera privada deverá prevalecer e o conteúdo em conflito não deverá ser publicado ou deverá ser excluído. Por outro lado, se o quociente for menor que 1, será o direito à liberdade de expressão que deverá preponderar. $\bigcirc$ ponto de toque para compreender a aplicação do método IBF está na "impossibilidade" de contestação do resultado da ponderação no presente ser realizada no futuro, pois os elementos de entrada podem se transformar com o tempo e são, absolutamente, condicionados por uma avaliação em certa conjuntura temporal. Isso significa que a aplicação da fórmula IBF para o mesmo caso poderá constituir duas decisões diferentes, levando em conta o aspecto temporal-circunstancial.

\section{Crítica alexyana: a fórmula WF como ponderação "única"}

A fórmula peso alexyana, elaborada no pós-escrito de A Theory of Constitutional Rights, está engendrada, desde 2003, da seguinte maneira:

$$
W i, j=\frac{I i^{*} W i^{*} R i}{I j^{*} W j^{*} R j}
$$

Wi,j reproduz um parâmetro para se ter o peso concreto de um princípio Pi, pode-se dizer, o direito à esfera privada, em relação ao princípio colidente $\mathrm{Pj}$, de liberdade de expressão. Essa fórmula busca definir o peso concreto conforme o quociente de três elementos que estão em cada lado da ponderação. Ii representa a intensidade da interferência com Pi, enquanto Ij realça a importância da satisfação do princípio colidente Pj e que pode se compreender como a intensidade de interferência, "isto é, como a intensidade de interferência com Pj por não interferência com Pi, Wi e Wj estão para os pesos abstratos dos princípios colidentes Pi e Pj”. Nos casos em que os pesos se equivalem, abstratamente, em conflitos de direitos, deixam de possuir alguma relevância, anulandose mutuamente. Ii e Ij e Wi e Wj englobam elementos da dimensão substantiva da ponderação, enquanto $\mathrm{Ri}$ e $\mathrm{Rj}$ se preocupam com a confiabilidade dos pressupostos empíricos e normativos que ordenam o nível de interferência com Pi e o grau que eventual interferência em Pj teria se a interferência em Pi fosse omitida. Ressalta-se que R, ou seja, a confiabilidade das condições empíricas e normativas, também, pode ser direcionada a Wi e Wj (pesos abstratos), além da necessária implicação nos elementos Ii e Ij (nível de interferências), pois Ri e Rj cuidam de uma preocupação epistêmica, e não, ôntica, na fórmula da ponderação. Ri = Rei . Rni. Veja-se que a equação da confiabilidade Rei (empírica) e Rni (normativa) poderá ela mesma se encontrar em conflito, resolvendo-se a questão mediante uma "refinação" da fórmula da ponderação. 
Para a ponderação alexyana, mesmo dispondo que a argumentação é a real "instituidora" dos elementos da fórmula WF (ela ocorre independentemente da fórmula), só é crível e racional se o quociente dos dois produtos em conflito e seus fatores se expressarem numericamente e é, justamente, com essa afirmação, que Alexy observa o problema das escalas que, a propósito, o autor também desenvolve. Na sua proposta de escala ("discreta"), tem-se os valores 1 (leve), 2 (moderado) e 3 (grave) no tocante à interferência (I) e aos pesos abstratos (W). No que diz respeito à $\mathrm{R}$ ou $\mathrm{R}$ em conflito (epistêmico), tem-se os níveis "confiável" (1), "plausível" (1/2) ou "não evidentemente falso" (1/4), podendo-se duplicar a escala "triádica", quando não for o bastante a "ordinária".

Os elementos da fórmula IBF sob a perspectiva da fórmula WF - Nota-se que a ponderação WF, mesmo que, também, possua "escalas", é altamente geral e abstrata e, além dessa distinção com a fórmula IBF, que é específica e concreta, é aplicável em conflitos de quaisquer direitos, não apenas entre "esfera privada e liberdade de expressão". Ademais, a WF é aplicável em contextos de confrontos entre mais de dois direitos, não tão somente em conflitos duais, como a IBF. Contudo, a principal distinção está no âmbito da atribuição dos pesos. Na WF, a atribuição dos pesos substantivos é articulada com base na argumentação, que ocorre, enfatiza-se, "fora da fórmula", embora exista uma conexão "necessária". Por outro lado, no método IBF, ocorre o contrário, justamente pelo "contexto ôntico e epistêmico" do "online", em que a "entrada dos pesos" é "sólida", recordando que a "argumentação" e a "transparência" estão no pressuposto mesmo da IBF. Outra diferença está na postulação pela IBF, da possibilidade de empate. Nos casos de empate, mostrase relevante a legitimidade de uma Corte Constitucional, mas a IBF não enfrenta, estritamente, essa questão, deixando para o elemento Empatia a incumbência de lidar com tais circunstâncias, destinando, por exemplo, aos "fundamentos morais quanto à igualdade" a equação a ser resolvida. Outra diferença está na condição de que a WF é equivalente em ambos os lados e níveis da equação, diferentemente da IBF, em que se encontram diversidades no lado direito (e também no esquerdo), estando a identidade apenas no elemento $\mathrm{E}(\mathrm{z})$, que permanece igual nos dois níveis da equação. Justificam-se essas diferenças pelos caracteres "ônticos" e "epistêmicos" da ponderação "online".

\section{A resposta de Mart Susi e a revisão da fórmula IBF}

A organização de uma resposta a Robert Alexy se detém nos aspectos específicos de sua crítica à IBF, ou seja, sobre o elemento vulnerabilidade da internet, a denominada tese da concretização e sobre o elemento empatia.

O elemento vulnerabilidade revisitado - O elemento V (1) tem a característica de ser uma constante 1 e possui, como pressuposto, o "contexto de comunicação no "online". Alexy rejeita o elemento $V(1)$ como peso abstrato maior à esfera privada, dizendo que a constante 1 significa um "fator definitivo" na fórmula, simbolizando "elementos da regra" na IBF. Susi entende que a compreensão de Alexy, nesse ponto, é oriunda de seu pressuposto teórico de "universalidade 
dos diretos humanos" ou a sua "independência prática", que deságua no entendimento sobre o questionamento de se o peso abstrato de determinado direito humano é absoluto independentemente de qualquer espaço-tempo. Com isso, exsurgem duas importantes observações. A primeira: se o peso de um direito é definido em "abstrato", poder-se-á ter conflito entre o "peso em abstrato ideal" de um direito e uma atribuição de peso pela normatividade teórica desenvolvida pela teoria dos direitos humanos. Isso demonstra o argumento de que poderá ser contraditória a afirmação de que um direito em abstrato detém um peso abstrato absoluto. A segunda: com efeito, se o peso de um direito depende de contextos, termina-se por rejeitar a defesa teórica de que direitos detêm pesos absolutos em abstrato, devido, preponderantemente, ao aspecto "prático dos direitos humanos", que "evolui" consoante contextos e da própria normatividade do Direito dos direitos humanos.

Complementando a sua resposta, Susi diz ser razoável afirmar que, no Direito Positivo, se encontram direitos com pesos "em abstrato" absolutos, relativos e os que não possuem o caráter de fundamentais/humanos. Dessa ideia, comenta Susi, pode surgir a conclusão de que, para a IBF e para a WF, se desconsiderarmos a $\mathrm{V}(1)$ como uma constante, ao mesmo tempo, "rejeitando" a vulnerabilidade como elemento de "intensidade da interferência", ambos os direitos sempre deverão se anular reciprocamente. É, exatamente, nessa hipótese, que se contrapõe o seu entendimento e fundamenta a sua rejeição às críticas de Alexy, porque compreende que certo direito pode possuir "múltiplos" pesos em abstrato, de acordo com o/um "tempo", e não, apenas "um peso em abstrato", como se percebe em Alexy. Para chegar a essa conclusão, Susi envereda, primeiramente, pela seguinte objeção: o "peso em abstrato de um direito" advém de uma abstração "ideal" ou de uma argumentação (das práticas, "explicação")? Veja-se que as posições das Cortes e dos órgãos legislativos, quando a favor da esfera privada nos conflitos de direitos no "online", expõem a nuance de uma constante a favor desse direito, sendo essa constante um peso em abstrato no "contexto" da internet. Dessa constatação, tem-se a concepção de que o "peso em abstrato" e a "intensidade - constante da interferência - são conceitos paralelamente interdependentes". A interferência "uniforme" em um direito pode se transformar em um peso em abstrato em relação a esse direito. Assim, é preciso admitir que o peso em abstrato é um elemento com o objetivo de ponderar dois direitos em conflito e que é pré-constituído antes do exercício mesmo da ponderação, sucedendo ser um elemento em abstrato, e não, "em concreto". É justamente, nessa posição, que se distingue a posição de Susi da de Alexy, pois, para aquele, a prática discursiva dominante sobre determinado direito pode constituir a sua normatividade/peso "em abstrato" e, para este, no caso, o elemento V(1) apenas representaria a "intensidade da interferência na esfera privada" como constante, resultado em Ii, não se podendo enquadrá-lo como peso em abstrato.

Outra disposição a favor da afirmação de que o peso em abstrato de determinado direito pode possuir mais de um "nível" em qualquer ordem temporal diz respeito a uma observação teórica sobre a doutrina dos direitos humanos. Por exemplo, do direito à esfera privada, advém o direito à integridade do corpo ou da "proteção genética". Esses dois direitos derivados não são, consensualmente, 
aceitos como "independentes", embora reivindiquem um peso em abstrato absoluto, nos casos de violação da integridade corporal ou na recusa de uma pessoa em conhecer o seu passado genético. O ponto está na seguinte questão: mesmo acatando-se o direito à esfera privada como geral e teoricamente relativo, deve-se aceitar que, em determinados contextos, existirão fundamentos sobre especificidades que configurarão um dever de maior proteção à esfera privada, "por reconhecer que sua natureza absoluta pode existir". Disso resulta a conclusão de que o peso de determinado direito pode possuir mais de um nível em um "mesmo tempo", desde que existam argumentos convincentes que demonstrem isso.

A fórmula IBF reformulada com base nas críticas de Alexy - Susi afirma que, com essa nova equação IBF, há um novo rumo para a ponderação "online". Tendo como objetivo revisar a fórmula IBF, retira-se o conceito Vulnerabilidade do lado do direito à esfera privada. $O$ argumento de que a esfera privada "merece mais proteção" no "online" deixa de influir na fórmula e, também, devido ao problema de se encontrar, por outro lado, outras posições defendendo que é a liberdade de expressão que "merece maior proteção" no "online". Assim, se aduz: na hipótese de, em algum outro momento, haver consenso sobre a constante $\mathrm{V}$, se aplicável à esfera privada ou à liberdade de expressão, essa constante poderá "retornar" à IBF. A IBF revisada se caracteriza pela inserção dos elementos "intensidade de interferência" e "peso abstrato", admitindo-se algumas das críticas de Alexy.

A mudança na fórmula se caracteriza pela exclusão do elemento Vulnerabilidade do lado do direito à esfera privada, adicionando-se o elemento "intensidade da interferência", "Ip" e "Ie", simbolizando-se, respectivamente, esfera privada e liberdade de expressão. Os outros elementos de entrada se mantêm, à exceção da colocação do peso em abstrato da esfera privada "Wp" e da liberdade de expressão (We). Se ambos os pesos se igualarem, haverá anulação recíproca desse elemento, assim, conduzindo-se com base na doutrina da monotonia dos direitos online e "off-line" ou da proteção igual no "online" e "off-line".

$$
\begin{aligned}
& \mathrm{IBF}=\mathrm{Ip}[\mathrm{PR}(\mathrm{x})+\mathrm{T}(\mathrm{y})+\mathrm{E}(\mathrm{z})]+\mathrm{Wp} \\
& \mathrm{Ie}[\mathrm{PI}(\mathrm{x})+\mathrm{PF}(\mathrm{x})-\mathrm{O} 1(\mathrm{y})+\mathrm{E}(\mathrm{z})]+\mathrm{We}
\end{aligned}
$$

Ressalta-se que Susi estabelece um escalonamento de 0 a 2 . 0 peso abstrato 2 aplicase aos direitos considerados absolutos. Nessa afirmação, tem-se a seguinte compreensão: Susi, anteriormente, demonstrou que, em determinados contextos, o direito à esfera privada poderá possuir um peso absoluto, desde que haja uma argumentação ("consensualmente") convincente. O mesmo se pode aplicar no caso do direito à liberdade de expressão, tendo em conta eventual circunstância política, social ou jurídica relevante, que "apresente" uma "necessidade de atribuir um peso absoluto" à liberdade de expressão. O peso abstrato 1 seria aplicável, quando o direito não puder ser classificado como "absoluto", mas tão somente quando "merecer mais proteção", em detrimento 
do outro direito em conflito, que manterá o peso 0. Como a fórmula IBF pretende ordenar decisões de conflito de direitos no "online", as empresas privadas, quando do uso da ponderação "online", nessa questão, deverão demonstrar o peso abstrato concedido para cada um dos direitos, sendo importante dizer que se pressupõe que o "peso em abstrato" imputado se pautará em fundamentos contundentes, não estando disposto a mudar ao sabor de qualquer razão fugaz.

A tese da concretização e o elemento Empatia - Alexy diz "que os elementos da IBF estão localizados em um nível abaixo da fórmula peso", chamando esse aspecto da IBF de "tese da concretização". A intensidade de interferência "I", na ponderação alexyana, é um dos três elementos mais importantes, enquanto o elemento da intensidade na IBF traduz concretos e variados elementos, em ambos os lados da equação. Susi diz não contestar a "tese da concretização", assumindo, inclusive, que esse aspecto "protege" a IBF e diz que é relevante para a demonstração de que a IBF é aplicável, enquanto ordenação das práticas "de proteção dos direitos humanos no domínio digital". De modo a demonstrar o seu argumento, decide-se comparar WF e IBF, nesse prisma. A fórmula WF é e foi muito criticada devido à generalidade dos elementos de entrada. Alguns disseram que o peso dependeria de uma "intuição"; outros, que essa "abertura" ou ausência de aspectos contundentemente racionais levariam a uma arbitrariedade. As variáveis da fórmula peso, para Alexy, representam classificações que não demandam fundamentação. A argumentação é adicionada a esse caldo teórico como que não vinculada à fórmula (ela ocorre independentemente da fórmula), e esse caráter "argumentativo dos elementos" justificaria a classificação formal da WF.

Na IBF, a tese da concretização auxilia a ponderação na internet, devido à justificação do valor em I, dos dois lados da fórmula, exatamente, porque os elementos orientadores do valor final de Ip e Ii, são conhecidos - conhece-se o restante dos elementos da fórmula. Na WF, a ausência de critérios "mais concretos é compensada pela argumentação". Essa distinção é muito relevante para a IBF, que possui, como finalidade, a decisão no "online", local em que as decisões precisam ser imediatas e em que a "argumentação" não é viável. Susi, assim, conclui que a tese da concretização detém a mesma finalidade na IBF, considerando o contexto do "online", da argumentação na fórmula WF, tal qual a ordenação da ponderação (racional) de direitos em circunstâncias conflitantes.

Sobre a Empatia, tem-se a referência de Alexy, notando dito elemento como sendo "o mais fraco", dado que, no intento de Susi de trazer a "moralidade" para a ponderação "online", há uma exposição "contraposta" entre "juízo moral" e "argumentação racional". Redarguindo as críticas alexyanas, Susi entende que está correta a posição de que juízos morais e argumentação racional não podem ser contrapostos, embora, também, não possam ser encarados como "sinônimos", pois ambos se integram nos discursos fundamentadores em direitos humanos/fundamentais. Desponta, como oportuno, notar que os discursos morais, nessa noção complementar com a "argumentação racional", podem, sim, ser racionais; porém, não é algo imprescindível, pois um juízo moral, mesmo constituído irracionalmente, é capaz de possuir pretensão de correção. Releva-se que o propósito do elemento Empatia é recuperar o "humano" nas decisões automatizadas, necessariamente, 
constituídas no "online", e isso influi nos dois contextos de decisão de direitos em conflito em tal esfera, em se operar a ponderação "online" em todos os casos de modo automatizado, sem intervenção humana, ou que, em determinados casos difíceis, a inteligência humana intervenha. Susi pressupõe, "intuitivamente", que é a segunda circunstância que a "maioria das pessoas" defende, e isso está ao lado de seu argumento a favor do elemento E, pois, como dito, em um juízo moral realizado, não se tem, como obrigatória, a fundamentação sobre o resultado desse juízo moral, sendo viável afirmar que certa circunstância "possa ser moralmente correta" dentro de um contexto social mais amplo, originando-se as conclusões morais de um sujeito por efeito de sua experiência e percepções morais gerais sobre a sociedade em que está inserido. Exatamente, por possuir essa característica, "o elemento E" constitui uma "tese da irracionalidade" para a fórmula IBF. O elemento Empatia, assim, mantém-se na fórmula IBF, para ser utilizado nos conflitos em que se obtenha "empate" ou em "casos difíceis", entretanto, deixando-se aberta a sua saída da fórmula, na hipótese de, no futuro, a inteligência artificial "tornar-se capaz" de realizar juízos morais ou na ocorrência de uma transformação paradigmática na proteção dos direitos humanos no "online", cujos indícios ainda não são aparentes em nosso horizonte.

\section{REFERÊNCIA}

SUSI, Mart; ALEXY, Robert. Proporcionalidade e internet. Porto Alegre: Sergio Antonio Fabris, 2020. 
